Acta Crystallographica Section E

Structure Reports

Online

ISSN 1600-5368

H. S. Yathirajan, ${ }^{a}$ B. Narayana,

M. Prathap, ${ }^{b} S$ Bindya ${ }^{c}$ and Michael Bolte ${ }^{d} *$

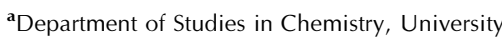
of Mysore, Manasagangotri, Mysore 570 006, India, 'b Department of Chemistry, Mangalore University, Mangalagangotri 574 199, India, cDepartment of Chemistry, Sri Jayachamarajendra College of Engineering, Manasagangotri, Mysore 570 006, India, and ${ }^{\mathbf{d}}$ Institut für Anorganische Chemie, J. W. Goethe-Universität Frankfurt, Max-von-Laue-Strasse 7, 60438

Frankfurt/Main, Germany

Correspondence e-mail:

bolte@chemie.uni-frankfurt.de

\section{Key indicators}

Single-crystal X-ray study

$T=173 \mathrm{~K}$

Mean $\sigma(\mathrm{C}-\mathrm{C})=0.002 \AA$

Disorder in main residue

$R$ factor $=0.050$

$w R$ factor $=0.136$

Data-to-parameter ratio $=15.6$

For details of how these key indicators were automatically derived from the article, see http://journals.iucr.org/e.

\title{
2-Hydroxy-3,5-diisopropylbenzoic acid
}

The title compound, $\mathrm{C}_{13} \mathrm{H}_{18} \mathrm{O}_{3}$, crystallizes with three independent molecules in the asymmetric unit. In the crystal structure, two of the molecules form a hydrogen-bonded dimer, while the third forms a centrosymmetric hydrogenbonded dimer with its symmetry-equivalent molecule. In each independent molecule, there is an intramolecular $\mathrm{O}-\mathrm{H} \cdots \mathrm{O}$ hydrogen bond.

\section{Comment}

Substituted hydroxybenzoic acids are used for the preparation of coumarin derivatives, which are known antibacterials (Friedman et al., 2003). Benzoic acid was among the first organic crystal structures to be examined by the application of X-ray crystallography (Bragg, 1921, 1922). Since then, numerous structures of benzoic acid and its derivatives have been reported (Sim et al., 1955; Parkin et al., 2005), owing to their importance in synthetic medicinal chemistry. The intermolecular association of carboxylic acid dimers in the supramolecular assembly of 2-(2-phenylethyl)benzoic acid has been reported (Anilkumar et al., 2005). In view of the importance of the title compound, (I), its crystal structure is reported here.<smiles>CC(C)c1cc(C(=O)O)c(O)c(C(C)C)c1</smiles>

(I)

In the structure of (I), there are three independent molecules in the asymmetric unit. A view of one of the independent molecules is shown in Fig. 1. In each molecule, bond lengths and angles can be regarded as normal (Cambridge Structural Database, Version 5.27, November 2005, updated August 2006; MOGUL, Version 1.1; Allen, 2002). The geometries of the three molecules in the asymmetric unit are almost identical and their molecular conformations are stabilized by intramolecular $\mathrm{O}-\mathrm{H} \cdots \mathrm{O}$ hydrogen bonds (Table 1).

In the crystal structure of (I), two symmetry-independent molecules form a hydrogen-bonded dimer, while the third molecule forms a centrosymmetric hydrogen-bonded dimer with its symmetry-equivalent molecule (Fig. 2). 


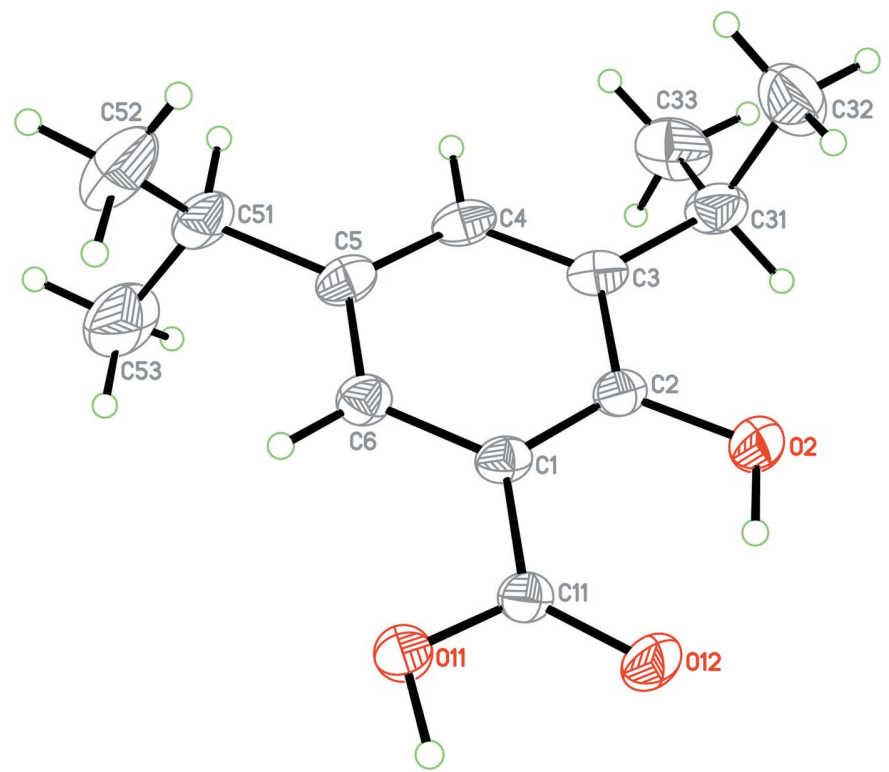

Figure 1

A view of one of the independent molecules of (I). Displacement ellipsoids are drawn at the $50 \%$ probability level.

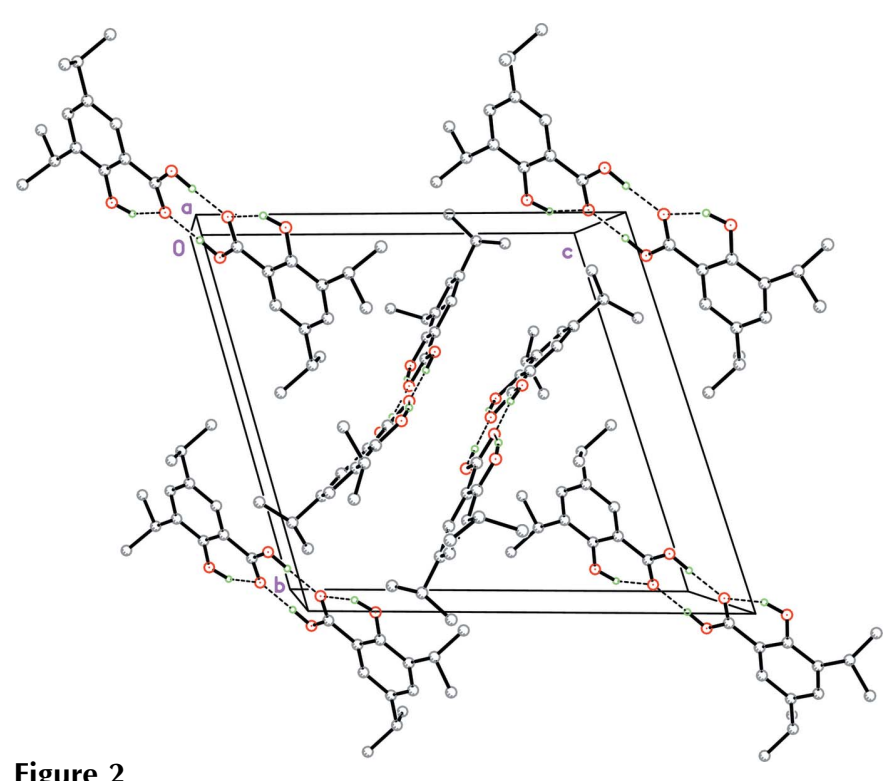

Figure 2

Part of the crystal structure of (I), viewed approximately perpendicular to the $b c$ plane. Hydrogen bonds are indicated by dashed lines. $\mathrm{H}$ atoms not involved in hydrogen bonding have been omitted. Only one disorder component is shown.

\section{Experimental}

Salicylic acid (13.8 g, $0.1 \mathrm{~mol})$ and propan-2-ol (12 g, $0.2 \mathrm{~mol})$ were heated with concentrated sulfuric acid $(25 \mathrm{ml})$ at $343-353 \mathrm{~K}$ for $1 \mathrm{~h}$, and the resulting mixture was then cooled and added to crushed ice. The resulting mass was filtered off and crystallized from ethanol. $\mathrm{X}$-ray diffraction quality crystals were obtained by slow evaporation of an acetone solution of (I) (yield 50\%; m.p. $391 \mathrm{~K}$ ). Analysis for $\mathrm{C}_{13} \mathrm{H}_{18} \mathrm{O}_{3}$, found (calculated): C 70.10 (70.24\%), H 8.11 (8.16\%).
Crystal data

$\begin{array}{ll}\mathrm{C}_{13} \mathrm{H}_{18} \mathrm{O}_{3} & V=1920.2(3) \AA^{3} \\ M_{r}=222.27 & Z=6 \\ \text { Triclinic, } P \overline{1} & D_{x}=1.153 \mathrm{Mg} \mathrm{m}^{-3} \\ a=9.2545(7) \AA & \text { Mo } K \alpha \text { radiation }^{-} \\ b=14.7627(13) \AA & \mu=0.08 \mathrm{~mm}^{-1} \\ c=15.2767(12) \AA & T=173(2) \mathrm{K} \\ \alpha=72.823(7)^{\circ} & \text { Block, colourless } \\ \beta=78.217(6)^{\circ} & 0.43 \times 0.41 \times 0.38 \mathrm{~mm} \\ \gamma=76.792(7)^{\circ} & \end{array}$

$\gamma=76.792(7)$

\section{Data collection}

Stoe IPDSII two-circle diffractometer

$\omega$ scans

Absorption correction: none

17863 measured reflections

\section{Refinement}

Refinement on $F^{2}$

$R\left[F^{2}>2 \sigma\left(F^{2}\right)\right]=0.050$

$w R\left(F^{2}\right)=0.136$

$S=1.05$

7147 reflections

457 parameters

$\mathrm{H}$ atoms treated by a mixture of independent and constrained refinement

7147 independent reflections 5551 reflections with $I>2 \sigma(I)$ $R_{\text {int }}=0.049$

$\theta_{\max }=25.6^{\circ}$ $+0.3735 P]$

where $P=\left(F_{\mathrm{o}}^{2}+2 F_{\mathrm{c}}^{2}\right) / 3$

$(\Delta / \sigma)_{\max }<0.001$

$\Delta \rho_{\max }=0.31{\mathrm{e} \AA^{-3}}^{-3}$

$\Delta \rho_{\min }=-0.38$ e $\AA^{-3}$

Extinction correction: SHELXL97 (Sheldrick, 1997)

Extinction coefficient: 0.0136 (19) $w=1 /\left[\sigma^{2}\left(F_{\mathrm{o}}{ }^{2}\right)+(0.0719 P)^{2}\right.$

Table 1

Hydrogen-bond geometry $\left(\AA{ }^{\circ}\right)$.

\begin{tabular}{lllll}
\hline$D-\mathrm{H} \cdots A$ & $D-\mathrm{H}$ & $\mathrm{H} \cdots A$ & $D \cdots A$ & $D-\mathrm{H} \cdots A$ \\
\hline $\mathrm{O} 2-\mathrm{H} 2 \cdots \mathrm{O} 12$ & $0.97(3)$ & $1.76(3)$ & $2.6162(19)$ & $146(3)$ \\
$\mathrm{O} 11-\mathrm{H} 11 \cdots \mathrm{O} 12^{\mathrm{i}}$ & $0.96(3)$ & $1.68(3)$ & $2.6374(17)$ & $174(2)$ \\
$\mathrm{O} 2 A-\mathrm{H} 2 A \cdots \mathrm{O} 12 A$ & $0.87(3)$ & $1.87(3)$ & $2.6417(16)$ & $147(3)$ \\
$\mathrm{O} 11 A-\mathrm{H} 11 A \cdots \mathrm{O} 12 B$ & $0.96(3)$ & $1.74(3)$ & $2.6891(15)$ & $175(2)$ \\
$\mathrm{O} 2 B-\mathrm{H} 2 B \cdots \mathrm{O} 12 B$ & $0.89(3)$ & $1.83(3)$ & $2.6420(16)$ & $150(2)$ \\
$\mathrm{O} 11 B-\mathrm{H} 11 B \cdots \mathrm{O} 12 A$ & $0.89(2)$ & $1.79(2)$ & $2.6724(15)$ & $172(2)$ \\
\hline
\end{tabular}

Symmetry code: (i) $-x+2,-y,-z$.

$\mathrm{H}$ atoms were found in a difference map, but those bonded to $\mathrm{C}$ atoms were positioned geometrically and allowed to ride on their parent $\mathrm{C}$ atoms at distances ranging from 0.95 to $1.00 \AA$ and with $U_{\text {iso }}(\mathrm{H})=1.2 U_{\text {eq }}(\mathrm{C})$ or $1.5 U_{\text {eq }}\left(\mathrm{C}_{\text {methyl }}\right)$. $\mathrm{H}$ atoms bonded to $\mathrm{O}$ atoms were refined independently with isotropic displacement parameters. In one independent molecule, two of the methyl groups of an isopropyl group are disordered over two sites with refined occupancy factors of $0.502(10)$ and $0.498(10)$. The disordered $\mathrm{C}$ atoms were refined isotropically.

Data collection: $X$-AREA (Stoe \& Cie, 2001); cell refinement: $X$-AREA; data reduction: $X$-AREA; program(s) used to solve structure: SHELXS97 (Sheldrick, 1997); program(s) used to refine structure: SHELXL97 (Sheldrick, 1997); molecular graphics: XP in SHELXTL-Plus (Sheldrick, 1991); software used to prepare material for publication: SHELXL and PLATON (Spek, 2003).

MP thanks Mangalore University for the provision of research facilities. SB thanks Sri Jayachamarajendra College of Engineering for financial assistance.

\section{References}

Allen, F. H. (2002). Acta Cryst. B58, 380-388. 


\section{organic papers}

Anilkumar, H. G., Yathirajan, H. S., Narasimhamurthy, T., Vijay, T. \& Rathore, R. S. (2005). Acta Cryst. E61, o2704-02705.

Bragg, W. H. (1921). Proc. Phys. Soc. London, 34, 33-50.

Bragg, W. H. (1922). J. Chem. Soc. pp. 2766-2787.

Friedman, M., Henika, P. R. \& Mandrell, R. E. (2003). J. Food. Prot. 66, 18111821.

Parkin, A., Harte, S. M., Carmichael, D., Currie, S., Drummond, L., Haahr, A., Haggarty, K., Hunter, T., Lamarque, A., Lawton, L., Martin, C., Mathieson, J. E., Mathieson, J. S., McGlone, T., McGregor, J., McMillan, L., Robertson,
L., Thatcher, R., Vance, S. \& Wilson, C. C. (2005). Acta Cryst. E61, o2280o2282.

Sheldrick, G. M. (1991). SHELXTL-Plus. Release 4.1. Siemens Analytical X-ray Instruments Inc., Madison, Wisconsin, USA.

Sheldrick, G. M. (1997). SHELXS97 and SHELXL97. University of Göttingen, Germany.

Sim, G. A., Robertson, J. M. \& Goodwin, T. H. (1955). Acta Cryst. 8, 157-164. Spek, A. L. (2003). J. Appl. Cryst. 36, 7-13.

Stoe \& Cie (2001). $X$-AREA. Stoe \& Cie, Darmstadt, Germany. 